\title{
Percepção de alunos de Pós-Graduação em Zootecnia da FAEM/UFPEL a respeito de sua capacitação para a docência
}

\section{Perception of Post-Graduation students in Animal Science of FAEM/UFPEL about their training for teaching practice}

\author{
Beatriz Simões Valente ${ }^{1}$ \\ Carla Gonçalves Rodrigues ${ }^{2}$
}

\begin{abstract}
RESUMO
Este estudo tem como objetivo investigar a contribuição do Programa de Pós-Graduação em Zootecnia da Faculdade de Agronomia Eliseu Maciel (FAEM) da Universidade Federal de Pelotas (UFPEL) para a formação e o exercício do trabalho docente a partir da percepção de alguns de seus alunos. A pesquisa caracteriza-se como qualitativa do tipo etnográfico, onde se utilizou para a coleta de dados um questionário e uma entrevista semiestruturada, que foi aplicada a seis doutorandos do referido Programa. Percebemos, por meio da análise das convergências e divergências das respostas obtidas, que o sentimento de insegurança e desconforto esteve presente durante a primeira experiência docente de todas as entrevistadas, o que parece ainda ser uma constante. Entretanto, ressaltam o estágio de docência orientada como um dos pontos positivos de sua formação dentro do Programa de Pós-Graduação em Zootecnia. Contudo, as alunas têm plena consciência de que a profissionalização docente não se baseia em uma perspectiva de ensaio e erro, em decorrência das aprendizagens que realizam com seus próprios alunos. Acreditam que sejam necessários os saberes pedagógicos da profissionalização do ofício docente, mesmo que muitas vezes não saibam quais. Desta forma, sugerem que disciplinas
\end{abstract}

${ }^{1}$ Doutoranda do Programa de Pós-Graduação em Zootecnia da FAEM/UFPEL, Brasil. E-mail: bsvalente@terra.com.br

${ }^{2}$ Doutora em Educação pela Universidade Federal do Rio Grande do Sul (UFRGS). Professora Adjunta da Universidade Federal de Pelotas, Brasil. E-mail: cgrm@ufpel.tche.br 
da área pedagógica sejam inseridas na grade curricular do Programa de Pós-Graduação em Zootecnia, sendo ministradas por professores da área da Educação.

Palavras-chave: educação superior; formação docente; prática pedagógica.

\begin{abstract}
This study aims to investigate the contribution of the Post-Graduation Program in Animal Science of Faculdade de Agronomia Eliseu Maciel (FAEM) from Universidade Federal de Pelotas (UFPEL) for the formation and the teaching practice from the perspective of some of its students. The study is characterized as qualitative and of the ethnographic kind. A questionnaire and a semi-structured interview applied to six doctorate students from the Program were used for the data gathering. Through the analysis of convergence and divergence of the obtained answers, it was noticed that the feeling of insecurity and discomfort was present during the first teaching experience of all interviewees. However, they emphasize the oriented teacher training as one of the strengths of their training within the Post-Graduation Program in Animal Science. Still, the students are aware that the teacher professionalization is not based on the perspective of trial and error as a result of the learning they have with their own students. They believe in the necessity of including pedagogical knowledge in the professionalization of the teaching profession, even if they often do not know what they are. They also suggest that pedagogical subjects are inserted into the educational curriculum of the Post-Graduation Program in Animal Science, being taught by professors from the Education field.
\end{abstract}

Keywords: higher education; teacher training; pedagogical practice.

\title{
Introdução
}

O Programa de Pós-Graduação em Zootecnia (PPGZ) da Faculdade de Agronomia Eliseu Maciel (FAEM) da Universidade Federal de Pelotas (UFPEL) foi criado em 1972. A criação do doutorado veio mais tardiamente, em 2002. Atualmente, é representado por 24 docentes, sendo 18 com título de doutor e seis pós-doutores. Tem por objetivo a formação de pessoal qualificado para o exercício das atividades de ensino, pesquisa e desenvolvimento nas áreas de Nutrição Animal, Melhoramento Animal, Pastagens e Produção Animal. Além das atividades relacionadas à Pós-Graduação, esses profissionais também 
ministram aulas a alunos de graduação dos cursos de Medicina Veterinária, Agronomia e Zootecnia.

Ao acessar a Plataforma Lattes, consultamos o currículo de cada um dos docentes do PPGZ. Os docentes são possuidores de uma vasta produção técnico-científica, porém com menor formação na área pedagógica. De acordo com Pachane (2003), devido à inexistência de um amparo legal que estimule a formação pedagógica dos professores universitários, a opção por proporcionar ou não esta formação fica a cargo dos regimentos de cada instituição que é responsável pelo oferecimento de cursos de Pós-Graduação, refletindo e, ao mesmo tempo, regulamentando a crença na não necessidade de que esta formação seja oferecida. Nogueira (1989) ressalta que uma das causas dessa realidade pode estar associada à reforma universitária de 1968, que estabeleceu como princípio norteador, para o desenvolvimento da universidade brasileira, a indissociabilidade entre ensino e pesquisa. Este princípio formal e obrigatório acabou por transformar os professores universitários em professores "preferencialmente" pesquisadores.

Desta forma, neste âmbito, o prestígio do professor alicerça-se basicamente nas atividades de pesquisa, incluindo as publicações de artigos em revistas nacionais e internacionais e também na participação em eventos científicos da área. É, ainda, valorizado pela atividade de orientação de dissertações e teses, bem como pela participação em bancas e processos ligados à Pós-Graduação. Consultorias e cargos na administração universitária também se constituem em um valor profissional. Neste contexto, o ensino de graduação é entendido como decorrência das demais atividades, assumindo uma forma naturalizada de exercício. Tardif (2007) contribui afirmando que as atividades de formação e de educação parecem passar progressivamente para o segundo plano.

Nesta perspectiva, o exercício da docência se produz de modo "natural", se referindo à manutenção dos processos de reprodução cultural, ou seja, o professor ensina a partir da sua experiência como aluno, que, durante o seu aprendizado, absorve visões de mundo, concepções epistemológicas, posições políticas e experiências didáticas de seus antigos professores. É o que Perrenoud (1993, p. 12) denomina de habitus profissional, que se constitui em "[...] um sistema de esquemas de percepção e de ação que não está total e conscientemente sob o controle da consciência". De forma consciente ou não, parece que os docentes deste âmbito foram formando e organizando seus esquemas cognitivos e afetivos para a sua docência futura.

O corpo discente do Programa de Pós-Graduação em Zootecnia da FAEM/ UFPEL está constituído por 48 alunos, sendo 27 de mestrado e 21 de doutorado e na sua maioria formados em Agronomia, Medicina Veterinária e Zootecnia. Desses discentes, 31 possuem bolsas da Coordenação de Aperfeiçoamento de 
Pessoal de Nível Superior (CAPES) e 11 alunos, bolsas do Conselho Nacional de Desenvolvimento Científico e Tecnológico (CNPq). De acordo com o regulamento do Programa de Demanda Social anexo à Portaria $n^{\circ} 52 / 002$, a concessão de quota de bolsas aos programas de Pós-Graduação stricto sensu é definida com base nos resultados do sistema de acompanhamento e avaliação, coordenado pela CAPES, com a finalidade de manter, em tempo integral, alunos de excelente desempenho acadêmico.

Esses alunos, além das disciplinas obrigatórias referentes ao primeiro semestre do Curso, também necessitam realizar o estágio de docência orientada, que está fundamentado no Art. 17 do Programa de Demanda Social. Neste artigo, lê-se que "o estágio de docência é parte integrante da formação do pós-graduando, objetivando a preparação para a docência e a qualificação do ensino de graduação, sendo obrigatório para todos os bolsistas do Programa de Demanda Social". Entretanto, este documento não menciona como deve ser realizada esta formação docente, deixando a critério do Programa de Pós-Graduação.

Neste estudo, temos como objetivo investigar a contribuição do Programa de Pós-Graduação em Zootecnia da FAEM/UFPEL para a formação e o exercício do trabalho docente a partir da percepção de alguns de seus alunos.

\section{Concepção e contextualização das bases empíricas e teóricas para o estudo}

Participaram do estudo seis doutorandos que obtiveram o título de mestre no PPGZ da FAEM/UFPEL e também se graduaram na referida Universidade. Optamos por delimitar a população do estudo a esses alunos por estarmos, durante o desenvolvimento da pesquisa, compartilhando desse cotidiano, ou seja, por também sermos discentes do referido Programa de Pós-Graduação. Neste sentido, Cunha (2007) ressalta que "[...] quanto mais inserido no meio que constitui objeto de estudo, mais oportunidade terá para dispor de dados relevantes".

A pesquisa caracteriza-se, predominantemente, como qualitativa do tipo etnográfico. Como instrumentos para coleta de dados, utilizamos um questionário e uma entrevista semiestruturada, que foi gravada, o que proporcionou uma maior liberdade à manifestação dos respondentes. Os sujeitos foram contatados pessoal e individualmente, com o propósito de apresentar-lhes o trabalho que estávamos desenvolvendo, procurando assim dissipar qualquer desconfiança quanto ao uso dos dados e também com o intuito de agendar os encontros individuais. É importante ressaltar que não houve reação negativa por parte dos 
indivíduos, muito pelo contrário. Embora todos os sujeitos fossem femininos, o trabalho não se caracteriza por um estudo de gênero.

Para André (1995, p. 111), a pesquisa etnográfica "se caracteriza fundamentalmente por um contato direto do pesquisador com a situação pesquisada, permite reconstruir os processos e as relações que configuram a experiência escolar diária”. Ainda a mesma autora acrescenta que por meio das técnicas etnográficas de observação e de entrevistas é possível desvelar os encontros e desencontros que permeiam o cotidiano da prática docente universitária. Além disso, possibilita descrever as ações e representações de seus atores sociais, bem como reconstruir a sua linguagem, suas formas de comunicação e os significados que são criados e recriados no cotidiano de seu fazer pedagógico.

O estudo, portanto, incluiu dois tipos de tratamento dos dados. O primeiro permitiu o agrupamento de informações consideradas relevantes, sobre a percepção dos sujeitos a respeito de sua capacitação para a docência. O segundo consistiu em buscar as convergências e divergências nas respostas obtidas nas coletas de dados.

\section{A formação de nossos futuros docentes frente às políticas da Coordenação de Aperfeiçoamento de Pessoal de Nível Superior}

A Coordenação de Aperfeiçoamento de Pessoal de Nível Superior (CAPES) foi criada em 11 de julho de 1951, pelo Decreto ${ }^{\circ} 29.741$, com o objetivo de assegurar a existência de pessoal especializado em quantidade e qualidade suficientes para atender às necessidades dos empreendimentos públicos e privados que visavam ao desenvolvimento do país. Era o início do segundo governo Vargas e a retomada do projeto de construção de uma nação desenvolvida e independente. Neste período, o entendimento de ensinar como sinônimo de transmitir um saber assumia um significado socialmente pertinente, quando o saber disponível era muito menor, pouco acessível e o seu domínio limitado a um número restrito de grupos ou indivíduos (ROLDÃO, 2007).

No decorrer dos anos, esta ideia foi sendo reforçada pelas diversas leis promulgadas, a exemplo da Lei de Diretrizes e Bases da Educação Nacional $\mathrm{n}^{\circ}$ 9.394/96, onde se preconiza que as instituições de ensino superior se adaptem à exigência de que pelo menos um terço do seu corpo docente apresente titulação acadêmica de mestrado e doutorado. Neste sentido, a CAPES, em 1999, reconhecendo a importância da formação de mestres e doutores para o ensino de nível superior, passou a incorporar no seu estatuto o estágio supervisionado de docência. 
Valendo-nos da situação, investigamos a partir dos sujeitos desta pesquisa se o estágio de docência orientada contribui para a formação docente do aluno do PPGZ/FAEM/UFPEL.

"Sim, nos proporciona um contato com os alunos e situações ocorrentes em sala de aula. Ocorre uma preparação de como atuar em sala de aula, apesar de faltar um pouco de orientação de como melhorar e incrementar. Além disso, a docência orientada funciona como estágio, onde você pode errar. Também nos leva a perder a timidez" (Doutoranda A).

"Sim, pois de certa maneira, estamos impostos a ministrar aulas para alunos do ensino médio e superior, ainda que não tenhamos uma orientação pedagógica sobre a melhor maneira de fazê-lo" (Doutoranda E).

Parece-nos que durante o estágio não são trabalhados com os discentes conhecimentos teóricos na área pedagógica, o que reforça a ideia de que para ensinar basta conhecer o conteúdo e ter experiência (GAUTHIER, 1998), que neste cenário é proporcionada pelo contato diário com os alunos, a sabor dos erros e dos acertos de cada discente entrevistado. Corroborando esta visão, Pimenta e Anastasiou (2002) comentam que a formação oferecida aos pós-graduandos separa-os de qualquer discussão sobre o pedagógico. Cunha (2004, p. 527), comungando deste pensamento, explica que

[...] a docência universitária recebeu forte influência da concepção epistemológica dominante, própria da ciência moderna, especialmente inspiradora das chamadas ciências exatas e da natureza, que possuía a condição definidora do conhecimento socialmente legitimado.

Outra importante medida foi a Lei $\mathrm{n}^{0} 11.502$, de 11 de julho de 2007, $\S 1^{\circ}$, que determina que no âmbito da educação superior a CAPES terá a finalidade de subsidiar o Ministério da Educação na formulação de políticas para Pós-Graduação. Além disso, tem a responsabilidade de coordenar e avaliar os cursos desse nível e estimular, mediante bolsas de estudo, auxílios e outros mecanismos, a formação de recursos humanos altamente qualificados para a docência de grau superior, a pesquisa e o atendimento da demanda dos setores público e privado. 
Em decorrência dessas políticas, os cursos de Pós-Graduação estão voltados para o desenvolvimento científico-tecnológico, assim como para a formação de docentes de nível superior. Entretanto, o primeiro propósito parece ser considerado prioritário. Tendo como pressuposto o paradigma da educação tradicional, o conteúdo técnico-científico assume um valor significativamente maior do que o conhecimento pedagógico e das humanidades na formação de professores, uma vez que o saber dos professores que aí atuam parece residir unicamente na competência técnica para transmitir conhecimentos. Corroborando esta afirmação, Tardif (2007, p. 43) havia chamado a atenção para essa condição dizendo que "nenhum saber é por si mesmo formador".

A fala de uma das alunas ilustra a situação vivida dentro do Programa de Pós-Graduação em Zootecnia da FAEM/UFPEL:

"[...] às vezes a pessoa não adianta saber tudo, como é o caso de um pesquisador. Eu tenho observado muitos pesquisadores que não são bons professores e também muitos professores que não são bons pesquisadores. Isto ocorre geralmente em Curso de Pós-Graduação" (Doutoranda D).

Isto revela que conhecer alguma coisa parece não ser mais suficiente, sendo necessário também se informar de como trabalhar o conteúdo técnico-científico produzido, a fim de contribuir para o aprendizado e para a socialização do indivíduo. Em suma, a busca de um saber da ação pedagógica em sala de aula se faz necessária para trabalhar os conteúdos disciplinares e, também, como forma de fomentar o interesse do aluno.

Esta situação parece ser estimulada diretamente pela avaliação da CAPES mediante critérios próprios, que compreendem parâmetros muito mais quantitativos de valoração dos programas e dos corpos docente e discente do que propriamente qualitativos. Nesta perspectiva, percebemos a necessidade de abordar dois critérios que consideramos importantes para o entendimento da realidade vivida pelos Programas de Pós-Graduação, no que tange às suas obrigações e preocupações.

a) Critérios de avaliação dos Programas de Pós-Graduação. Neste quesito, a eficiência dos programas na formação de mestres e doutores é avaliada pelo tempo médio de formação de seus discentes, que são valorados também pela sua atuação acadêmica, onde a CAPES leva em consideração os prêmios recebidos. Os docentes também são avaliados quanto a sua atuação acadêmica, compreendendo assim as participações especiais em órgãos oficiais como a CAPES e o CNPq, como editores de periódicos "Qualis A ou B", como consul- 
tores de periódicos internacionais e também como representantes de sociedades de classe. Adicionalmente, o impacto educacional dos programas é avaliado pela produção de materiais técnicos e didáticos, bem como pela atividade de recursos humanos em cursos lato sensu.

b) Critérios de avaliação do corpo docente. A CAPES impõe aos programas que o seu corpo docente seja formado por doutores, sendo que estes devem possuir experiência, ter perfil acadêmico, produção e maturidade técnico-científica adequada. Também são avaliados o perfil e a adequação dos docentes permanentes quanto à especialidade, abrangência e a relação com a área de concentração, linhas e projetos de pesquisa, atividades de formação, orientações de teses e dissertações, bem como a sua produção intelectual. Neste caso, a elevada proporção de bolsistas de pesquisa CNPq é altamente desejável. Além disso, o docente é valorado pela sua especialidade na área de pesquisa e ensino em que atua.

Desta forma, tudo indica que os critérios em que a CAPES se baseia valorizam muito mais a produção técnico-científica dos seus docentes e discentes. Tomam como pressuposto a universalidade de espaços e territórios como se a situação dos Programas de Pós-Graduação e dos estudantes fossem as mesmas. Em outro sentido, não há nenhum critério qualitativo de avaliação de formação docente quanto aos saberes pedagógicos. Além disso, em nenhum momento é mencionado que esses saberes pedagógicos devam fazer parte da estrutura curricular dos futuros docentes de ensino superior, negligenciando assim a sua preparação para o ensino, o que contribui para a ideia de que ser apenas um especialista no seu campo de conhecimento basta para o exercício da profissão docente.

Corroborando esta ideia, Cunha (2004, p. 527) afirma que:

[...] a carreira universitária se estabelece na perspectiva de que a formação do professor requer esforços apenas na dimensão científica do docente, materializada pela pós-graduação stricto sensu, nos níveis de mestrado e doutorado. Explicita um valor revelador de que, para ser professor universitário, o importante é o domínio do conhecimento de sua especialidade e das formas acadêmicas de sua produção.

Neste contexto, o depoimento exemplifica a situação gerada pelas atuais políticas: 
"O aluno acaba entrando na realidade e agindo da mesma forma, ou seja, fazendo aquilo que não é o certo. Na maioria das vezes ele segue uma cartilha, que é seguida há anos pelos profissionais e não consegue botar as ideias dele em prática ou dar sugestões para as melhorias" (Doutoranda E).

Diante desta perspectiva, parece que os saberes docentes se fundamentam no reforço da condição de visão única, ou seja, na produção de conhecimentos técnico-científicos. Esta condição, possivelmente, tenha sido estimulada pelos critérios produtivos de avaliação da CAPES, que indicam alguma "padronização" desses sujeitos.

\section{Orientações teóricas e práticas na formação da docência do aluno de Pós-Graduação em Zootecnia}

No decorrer das suas falas, constatamos a importância do estágio de docência orientada para os alunos do Programa de Pós-Graduação em Zootecnia no que tange ao desenvolvimento de suas habilidades docentes. Relembramos que o desenvolvimento de suas habilidades é realizado por meio de aulas ministradas a alunos de graduação em Medicina Veterinária, Agronomia e Zootecnia, fazendo com que esses futuros docentes "[...] percam a timidez [...]" (Doutoranda B) e "[...] aprendam a planejar uma aula" (Doutoranda E). Desta forma, procuramos saber como foi e está sendo realizada a sua orientação para a docência superior. Para isso, primeiramente, pedimos a cada interlocutor um relato de sua primeira experiência como docente, que se fez durante o mestrado realizado no referido Programa. Convém lembrar que os dados foram obtidos por meio de entrevista semiestruturada, o que proporcionou espaço para cada um dos sujeitos comporem sua resposta de maneira própria. Assim, concluímos que suas verbalizações são valorativas, sendo necessária serem consideradas. Entretanto, o fato de serem ressaltados, pelos respondentes, alguns aspectos e silenciados outros, nos leva a acreditar que há significados próprios subjacentes às suas palavras.

"Não foi tão ruim, porque eu já tinha certa experiência da graduação em função de ter participado do programa de educação tutorial, que já nos preparava para este tipo de coisa. A gente atuava em ensino, pesquisa e extensão. Antes disso, eu não conseguia nem falar. Outra coisa, que me 
ajudou muito, foi que na minha primeira aula eu dominava o conteúdo que iria ministrar. Eu sabia que qualquer pergunta que viesse dos alunos eu estaria preparada" (Doutoranda A).

Ao analisarmos as verbalizações, percebemos que os sentimentos de insegurança e desconforto estiveram presentes, durante a primeira experiência como docente, em todas as interlocutoras, traduzindo-se assim nas expressões "Eu tremia que nem vara verde", "[...] eu estava muito nervosa [...]" (Doutoranda E), "Na verdade, assim, fiquei nervosa? Fiquei. A perna tremeu? Tremeu. Deu uma dorzinha na barriga? Deu" (Doutoranda C), "Foi crítica a coisa, [...] a voz quase não saiu" e "Eu não tinha muita experiência para falar, foi horrível [...]" (Doutoranda D).

"Na verdade, fiquei nervosa, a perna tremeu, deu uma dorzinha na barriga. Na primeira aula que ministrei, eu falei um pouco rápido no início, meio que atropelei. Desta forma, devido às recomendações do fulano resolvi procurar um curso de formação pedagógica. Hoje, eu tenho mais tranquilidade para escrever um plano de aula, para organizar a aula, para direcionar o aluno. Desde a minha primeira aula, eu acho que melhorei bastante" (Doutoranda C).

"Foi uma situação crítica (risos), [...] a voz quase não saiu. Então, claro, a primeira vez que se está dando aula, um público diferente e ainda o teu orientador te avaliando, é uma coisa que atrapalha. Na presença dele, além de ficar preocupada em passar a aula, fico também preocupada em saber se ele está achando certo. Na verdade, geralmente o que os orientadores querem é que tu fiques igual a eles" (Doutoranda D).

Além disso, alguns sujeitos ressaltaram o planejamento de suas aulas, que nas falas se traduz por meio da utilização de recursos didáticos, como o retroprojetor e o multimídia e, também, o domínio do conteúdo, como sendo importantes para atingir o sucesso no seu trabalho docente. Contudo, Gauthier (1998) ressalta que os professores que planejam de uma maneira demasiado rígida e detalhada se concentram demais no conteúdo e não o bastante nas necessidades dos alunos. Esta situação pode impedi-los de interagir com os alunos, de tirar proveito das ideias que eles expressam, bem como das oca- 
siões de discussão que surgem, porque estão muito centrados no seu plano de ação. Novamente, percebemos que os saberes parecem se limitar ao domínio cognitivo e instrumental do exercício do trabalho, esquecendo-se assim de uma socialização da profissão docente.

Ainda, vislumbramos, por parte de uma das alunas, o desejo de alterar este processo de naturalização, que se manifesta, muitas vezes, em decorrência do habitus profissional e da identidade institucional. Desta forma, o faz com a busca por um curso de formação pedagógica, a fim de teorizar e complementar a sua prática, realizada durante o estágio de docência orientada. Este fato demonstra uma mudança na percepção de algumas alunas, no que tange aos saberes necessários para a formação docente universitária. Cunha (2006, p. 259) complementa quando afirma que

Intervir nesse processo de naturalização profissional exige uma energia sistematizada de reflexão, baseada na desconstrução da experiência. Os sujeitos professores só alteram suas práticas quando são capazes de refletir sobre si e sobre sua formação.

Neste cenário, a reflexão crítica parece manifestar-se individualmente, de maneira silenciosa, permitindo assim, ao sujeito, uma intervenção de forma ativa e construtiva na sua própria formação docente, para então o fazer de forma coletiva. Para isso, tomamos este artigo como um instrumento balizador e fomentador desta transição paradigmática coletiva. Rever a capacitação docente do aluno do PPGZ/FAEM/UFPEL, face às mudanças de paradigma, é repensar conjuntamente a inovação, buscando assim compreender as atividades de ensino, pesquisa e aprendizagem.

A partir deste momento, retomamos a entrevista para elucidar de que forma é realizada a orientação dessas alunas durante o estágio de docência orientada. Num primeiro momento, observamos que os sujeitos são submetidos a formas diferentes de orientação, sendo esta dependente do professor orientador. Para exemplificar, valemo-nos das falas das alunas entrevistadas.

"Na verdade eu fiz o estágio de docência orientada com mais de um professor. Teve dois casos diferentes. Um dos professores acompanhou as aulas. $\mathrm{O}$ outro professor me deixou sozinha com os alunos, a aula era dada por mim. O professor deveria estar lá me orientando e dizendo não foi bem nisso, não foi bem naquilo. Diferente da outra disciplina, 
que o professor sempre me acompanhou e no final levantava os pontos positivos e negativos, o que estava errado e o que eu teria que fazer para melhorar" (Doutoranda A).

Neste contexto, as alunas são conduzidas pelos professores experientes através de uma orientação biforme, o que, de certa forma, pode ser positivo se forem complementares. Do contrário, esta orientação, em formato bifurcado, acarretará um confundimento dos sujeitos. Falamos isso porque os saberes experienciais dos professores são decorrentes de sua própria história e de sua socialização, fazendo com que esses atores assumam identidades próprias.

Em outro cenário, percebemos uma relação de confiança entre o professor experiente e o seu orientado que, muitas vezes, pode ser confundida por outros como uma menor valoração do ato de orientar para a docência.

"Na verdade, não foi realizada. A minha orientadora já me conhecia da época da graduação e ela sempre me deixou muito livre. A primeira aula, que fui ministrar, ela me apresentou para os alunos, assistiu ao início da aula e depois foi fazer as coisas dela. Deste momento em diante, eu sempre vou sozinha. Sempre vai um colega para ajudar no audiovisual" (Doutoranda B).

Em um terceiro momento, vislumbramos as falas de outras duas alunas e constatamos divergências significativas nas formas como estão sendo orientadas. Sentimos a necessidade de fragmentar seus depoimentos para, então, salientar as contradições. Desta forma, "Na verdade eu tive o apoio do fulano no início, em uma aula e ele foi bastante crítico, ele acompanhou, a gente discutiu antes e depois [...]" (Doutoranda C) e "Ele gosta muito de interferir na aula, ele para muitas vezes a aula" (Doutoranda F). Este fato comprova que o saber docente é plural e temporal, podendo repercutir de uma forma menos positiva na orientação do futuro docente quando este é acompanhado por dois professores orientadores.

Outra forma de orientação, exercida pelo professor experiente, é a de que o aluno, primeiramente, seja um espectador do seu trabalho. Desta forma, o orientador procura fornecer subsídios ao sujeito para a compreensão da docência, através de sua própria ação no âmbito universitário. Por outro lado, reforça o habitus profissional, caracterizando assim o saber social (TARDIF, 2007, p. 12). 
"Primeiro, o meu orientador fez com que eu assistisse às suas aulas, até para ter uma ideia de como é ministrar uma aula, de como eu deveria me portar, a sequência da apresentação e, principalmente, como me relacionar com os alunos" (Doutoranda D).

Após a compilação dos depoimentos, um último olhar nos fez vislumbrar que existem diversas formas de exercer a orientação para a formação docente do futuro profissional. No entanto, estas formas estão relacionadas às experiências anteriores de cada professor experiente. Tardif (2007, p. 160) complementa quando afirma que "ensinar é fazer escolhas, constantemente, em plena interação com os alunos. Ainda, ressalta que as escolhas são dependentes da experiência dos atores, do contexto de tempo e território do ensino, das convicções e crenças que suportam o trabalho e, consequentemente, de situações que, sendo únicas, exigem respostas diferenciadas.

Ainda, nos depoimentos, percebemos divergências nas respostas dos sujeitos quanto à necessidade da presença do professor orientador durante o estágio. Para algumas, a presença do profissional experiente se torna importante para apontar as falhas "[...] quanto à postura", "[...] ao falar muito rápido" e "[...] ao gesticular muito". Desta forma, as alunas demonstram concordar que as críticas, sejam elas positivas ou negativas, contribuem para a sua capacitação docente, sendo assim ilustrada em uma das falas:

“[...] eu até gosto que sejam críticos comigo porque é a maneira que eu tenho de aprender. Do contrário, eu posso estar errando e achando que estou fazendo a 'oitava maravilha do mundo'. Eu posso estar achando que os alunos estão entendendo e não estão. Então, a pessoa que está de fora consegue captar se estou sendo clara com os alunos, porque às vezes os alunos não falam" (Doutoranda $\mathrm{C}$ ).

Para outra aluna, a presença do professor orientador impede a livre manifestação de características que são inerentes a cada indivíduo e que são norteadoras de suas práticas dentro da sala de aula. Valemo-nos da sua verbalização para exemplificar:

"Eu acho que a presença do orientador na aula me deixaria muito constrangida. $\mathrm{O}$ orientador tem que saber que o seu orientado é capaz de 
ministrar uma aula. Se o orientado tem dificuldade, faz um treinamento antes. Eu acho que, querendo ou não, a gente está na frente dos alunos de graduação como formadora de opinião e, se tu não tens a tua opinião, se precisa da aprovação de outra pessoa para ter! Eu não consigo me libertar totalmente. Essa liberdade me fez crescer muito porque eu me autoavalio. Eu sei direitinho quais são os meus defeitos" (Doutoranda B).

Neste cenário, a futura docente prefere assumir uma posição ativa de sua própria prática, que é organizada a partir da sua vivência, de sua história de vida, de sua afetividade e de seus valores. Entretanto, deixar esta aluna experimentando uma pedagogia da prática construída solitariamente no seu cotidiano pode também acabar prejudicando-a no seu aprendizado profissional.

De fato, a presença do professor orientador, com suas constantes interrupções, pode levar a um descrédito deste futuro professor perante os alunos de graduação, o que pode prejudicar a estruturação de sua prática e, também, a aquisição do sentimento de competência para o exercício do trabalho docente. Cortesão (2002, p. 40) explica que "os docentes universitários ensinam geralmente como foram ensinados, garantidos pela sua prática e por uma socialização idêntica àquela de que eles próprios foram objetos".

Neste cenário, seria importante a troca coletiva das aprendizagens das experiências, que servirão como base para a sua profissionalização docente futura. Assim, Tardif (2007) explicita que os pensamentos, as competências e os saberes dos professores ultrapassariam as realidades estritamente subjetivas, sendo assim socialmente construídos e partilhados.

\section{Formação pedagógica de alunos de Pós-Graduação: necessária ou desnecessária?}

As contribuições anteriores dos sujeitos fizeram-nos vislumbrar a insegurança e o desconforto de suas primeiras experiências como docentes, o que parece ainda ser uma constante. A partir deste momento, procuramos saber, dos sujeitos entrevistados, se achariam necessário o conhecimento de saberes pedagógicos para a sua formação docente. Salientamos que todas as respondentes fizeram alusão à formação pedagógica como uma necessidade para a sua capacitação docente. Desta forma, ressaltamos algumas verbalizações. 
'Sim, pois dentro de um curso de Pós-Graduação 'convencional' não obteremos formação suficiente para executar atividades de ensino. Nos cursos de Pós-Graduação temos a execução da docência orientada, mas falta base teórica da arte de ensinar" (Doutoranda A).

"Sim, porque se estamos nos preparando para ser docentes, o mínimo que devemos ter ou estudar um pouco são as práticas pedagógicas, práticas de ensino" (Doutoranda C).

Os sujeitos do estudo creem que a profissionalização docente não se baseia em uma perspectiva de ensaio e erro, em decorrência das aprendizagens que realizam com seus próprios alunos. Acreditam que, para isso, sejam necessários os saberes pedagógicos da profissionalização do ofício docente, mesmo que muitas vezes não saibam quais. Entretanto, retomam o estágio de docência orientada como um dos pontos positivos em sua formação dentro do Programa de Pós-Graduação em Zootecnia.

"O estágio tem o seu valor porque a gente acaba ministrando várias aulas e acaba tendo mais experiência, já que cada aula é ministrada de uma maneira diferente. Se pensa de uma maneira diferente. Depende do aluno querer melhorar a sua didática. Então eu acho que se tiver uma disciplina só para isso iria complementar. Eu acho que não é só a prática" (Doutoranda E).

Outra interlocutora também salienta, com certa propriedade, a necessidade de disciplinas, na grade curricular do Programa, que contemplem a área pedagógica.

"Na época em que procurei o curso pedagógico, eu constatei que o que era repassado para nós, alunos da Pós-Graduação, era praticamente nada sobre esse assunto. Acredito que devam investir mais, porque não basta saber, deve-se saber repassar para o aluno" (Doutoranda C).

No contexto destas reflexões, constatamos que alguns sujeitos, tomados de percepção e, também, pela reflexão crítica dos fatos vivenciados, estão, mesmo 
que solitária e silenciosamente, trilhando um caminho onde a problematização de como vem sendo realizada a sua capacitação para a docência superior tornou-se um elemento instigador e provocador do desejo de um embasamento teórico pedagógico às suas práticas de sala de aula.

Para finalizar, valemo-nos das falas e das sugestões das alunas, no que se refere aos desejos de ressignificação dos conhecimentos experienciais já adquiridos.

"Eu acho que teria que ter uma base teórica a fim de saber com funciona essa questão do ensino. O estágio de docência orientada não nos proporciona isso. A gente não entende, não temos uma formação, apenas ministramos aulas. Passamos para o aluno apenas o conhecimento técnico-científico, mas não conhecemos o que é ensinar, o que é o conhecimento, o que é a ciência. Na verdade, vamos ministrar uma aula como se fôssemos palestrar para um produtor" (Doutoranda A).

As futuras docentes reconhecem que suas fragilidades dizem respeito, principalmente, a saberes e competências do campo pedagógico. Estão conscientes da necessidade de múltiplos saberes para a sua profissionalização, além daqueles adquiridos durante o estágio de docência orientada. Vamos mais longe, ao dizer que as alunas entrevistadas, mesmo sofrendo influência do habitus profissional e da identidade institucional, se permitem refletir sobre a sua prática docente, buscando assim respostas e soluções para as suas dificuldades, se deixando levar, muito pouco, pelas influências externas. Assim, exteriorizamos alguns depoimentos para ilustrar o que já foi dito.

"Eu acho que deveria ter um pouco mais com relação à parte pedagógica, talvez uma ou duas disciplinas optativas. Tem aqueles que também não querem ser docente, querem apenas ser pesquisador” (Doutoranda C).

"A nossa formação é muito técnica, tinha que ter uma parte mais pedagógica, uma disciplina que fosse. Quem te diz mais ou menos, como é que tu tens que ser, é o teu orientador, que também não tem nenhuma formação nessa área" (Doutoranda F). 
Desta forma, sugerem que disciplinas da área pedagógica sejam inseridas na grade curricular do Programa de Pós-Graduação em Zootecnia, sendo ministradas por professores da área da Educação. Ressaltam que essas disciplinas poderiam ser optativas, já que, sendo um Programa stricto sensu, também formam pesquisadores, ficando assim a sua inclusão no plano de estudo a critério de cada aluno de mestrado e doutorado.

"O PPGZ não deveria nos jogar na frente dos alunos para ministrarmos uma aula. Acho que deve ter uma preparação maior. A gente observa que a maioria dos professores também não teve essa formação, então não sabe como fazer isso. Uma pessoa específica na área, que pudesse fazer essa preparação, tanto da parte de como dar uma aula, como usar os meios (multimídia), de utilizar um fundo adequado no slide, fazer um plano de trabalho" (Doutoranda D).

No entanto, alguns respondentes desconhecem o universo pedagógico. Neste sentido, fragmento uma das falas, "[...] uma pessoa específica na área que pudesse fazer essa preparação, tanto da parte de como dar uma aula, usar os meios (multimídia), de utilizar um fundo adequado no slide, fazer um plano de trabalho", exemplificando assim esta afirmação. A pedagogia não pode ser vista unicamente como uma técnica a ser empregada, mas sim como uma prática social. Nesta perspectiva, "o professor é o sujeito do seu próprio trabalho e o ator de sua pedagogia" (TARDIF, 2007, p. 149).

\section{Considerações finais}

Alguns aspectos específicos emergem do conjunto de ideias analisadas sobre a percepção de alunos de Pós-Graduação em Zootecnia da FAEM/UFPEL a respeito de sua capacitação para a docência, ficando evidente que os saberes docentes se fundamentam no reforço de conhecimentos técnico-científicos da área, bem como em uma prática experiencial que se realiza por meio do estágio de docência orientada. A prática é proporcionada de forma abrupta, o que produz uma sensação de vivência instantânea, pontual e fragmentada do exercício do trabalho docente. Os saberes pedagógicos, fundamentais para profissionalização docente dos sujeitos, se encontram em um plano menor de valoração. Os 
critérios produtivos de avaliação da CAPES dos Programas de Pós-Graduação surgem como um fomentador desta situação, o que acaba gerando uma padronização dos sujeitos. Os indivíduos, sejam eles discentes ou docentes, são tomados por uma identidade institucional, resultando em um comportamento de habitus profissional, gerando assim "[...] um saber partilhado por todo um grupo de agentes que possuem uma formação comum, trabalham numa mesma organização e estão sujeitos [...] a condicionamentos e recursos comparáveis [...]", definindo um saber social (TARDIFF, 2007, p. 12).

Neste âmbito, o saber experiencial é adquirido no exercício prático do trabalho docente, que está, consciente ou inconscientemente, fundamentado na ideia de Descartes, que converteu a experiência em experimento, passando a ser o conhecimento uma mera acumulação progressiva de verdades objetivas. Este movimento valoriza o genérico, o repetível e o consenso, que, sendo características experimentais, levam à homogeneidade dos sujeitos, ficando desconsiderada a reação subjetiva ao objetivo. O saber experiencial passa a ser estritamente instrumental, caracterizando um saber que vem do fazer, sendo adquirido pelos sujeitos, durante o mestrado e o doutorado, ao realizarem o estágio de docência orientada. Desta forma, mesmo que os futuros professores sejam conscientes de que a profissionalização docente não se baseia em uma perspectiva de ensaio e erro e de que suas fragilidades dizem respeito a saberes e competências do campo pedagógico, os seus saberes experienciais se transformam muito cedo em certezas profissionais, em truques do ofício, em rotinas e em modelos de transmissão de conteúdos.

De outra forma, quando pensamos o saber experiencial a partir do par experiência/sentido (BONDÍA, 2002), vislumbramos que as orientações recebidas, durante o estágio de docência orientada, não se constituem em experiências para os referidos discentes do Programa, já que são meramente informações técnicas de uma área específica do conhecimento. O saber experiencial se difere do saber científico e do saber da informação, bem como da práxis profissional. De forma contrária, ele se dá na relação entre o conhecimento e a vida humana. No contexto do par experiência/sentido, o conhecimento não é adquirido através de informação, mas sim a partir do que nos toca, do que nos acontece, do que nos afeta, quando estamos em contato com nossos alunos, ou seja, no exercício de uma práxis docente. Neste cenário, o saber da experiência é um saber particular, subjetivo, relativo, contingente e pessoal, que nos forma e nos transforma. Nesta perspectiva, o futuro docente será o sujeito da experiência descrito por Bondía (2002, p. 21): “[...] um sujeito alcançado, tombado, derrubado. [...], podendo ser transformado por tais experiências no transcurso do tempo".

Este sujeito, tomado de experiência, se define por sua passividade, por sua receptividade, por sua disponibilidade e por sua abertura. É um indivíduo 
exposto, com tudo que isso tem de vulnerabilidade e risco. A experiência e o saber que dela deriva é o que lhe permite apropriar-se da significação da sua prática, criando assim modos de atuação que não consistem apenas em habitus profissional.

\section{REFERÊNCIAS}

ANDRÉ, M. E. D. A. de. A contribuição da pesquisa etnográfica para a construção do saber didático. In: OLIVEIRA, M. R. N. S. O. Didática: ruptura, compromisso e pesquisa. Campinas: Papirus, 1995.

BONDÍA, J. L. Notas sobre a experiência e o saber de experiência. Revista Brasileira de Educação, n. 19, p. 20-28, 2002.

CORTESÃO, L. Ser professor: um ofício em risco de extinção? Portugal: Afrontamento, 2002.

CRITÉRIOS DE Avaliação Trienal (2004-2007) da Coordenação de Aperfeiçoamento de Pessoal de Nível Superior. Disponível em: <http://www.capes.gov.br/images/stories/ download/avaliacao/CA2007_CienciasAgrarias.pdf>. Acesso em: 08/07/2009.

CUNHA, M. I. da. Diferentes olhares sobre as práticas pedagógicas no ensino superior: a docência e sua formação. Educação, v. 54, n. 3, p. 525-536, 2004.

. Docência na universidade, cultura e avaliação institucional: saberes silenciados em questão. Revista Brasileira de Educação, v. 11, n. 32, p. 258-271, 2006.

. O bom professor e sua prática. São Paulo: Papirus, 2007.

GAUTHIER, C. Ensinar: ofício estável, identidade profissional vacilante. In: Por uma teoria da pedagogia. Ijuí: Editora Unijuí, 1998.

NOGUEIRA, M. A. Universidade, crise e produção do saber. In: BERNARDO, M. (Org.). Pensando a educação. São Paulo: UNESP, 1989.

PACHANE, G. G. A importância da formação pedagógica para o professor universitário: a experiência da Unicamp. Tese (Doutorado em Educação) - Faculdade de Educação, Unicamp. Campinas, 2003.

PERRENOUD, P. Práticas pedagógicas - Profissão docente e formação: perspectivas sociológicas. Lisboa: Publicações Dom Quixote, 1993.

PIMENTA, S. G.; ANASTASIOU, L. G. C. Docência no Ensino Superior. São Paulo: Cortez, 2002. 
VALENTE, B. S.; RODRIGUES, C. G. Percepção de alunos de Pós-Graduação em...

REGULAMENTO DO Programa de Demanda Social. Portaria no 52/002. Disponível em: <http://www.capes.gov.br/sobre-a-capes/legislacao/2340-portarias $>$. Acesso em: 08/07/2009.

ROLDÃO, M. do C. Função docente: natureza e construção do conhecimento profissional. Revista Brasileira de Educação, v. 12, n. 34, p. 94-181, 2007.

TARDIF, M. Saberes docentes e formação profissional. Petrópolis: Vozes, 2007.

Texto recebido em 21 de julho de 2010.

Texto aprovado em 29 de julho de 2010. 